(2)

OPEN ACCESS

\title{
Online contraceptive discussion forums: a qualitative study to explore information provision
}

\author{
Tom Courtenay (D), Paula Baraitser
}

SH:24 Community Interest Company, London, UK

\section{Correspondence to} Dr Tom Courtenay, SH:24 Community Interest Company, 35a Westminster Bridge Road, South Bank, London SE1 7JB, UK; thomascourtenay9@gmail.com

Received 27 May 2020 Revised 22 July 2020

Accepted 28 July 2020 Published Online First 25 August 2020
D) Check for updates

(c) Author(s) (or their employer(s)) 2021. Re-use permitted under CC BY-NC. No commercial re-use. See rights and permissions. Published by BMJ.

\footnotetext{
To cite: Courtenay T, Baraitser P. BMJ Sex Reprod Health 2021;47:e5.
}

\begin{abstract}
Background Women in the UK spend up to 30 years avoiding pregnancy, and effective use of contraception requires detailed information and support. Online forums offer opportunities to discuss contraception with few restrictions. Analysis of these discussions may generate learning on the information needs and preferences of their users. We analysed contraceptive discussions on forums to explore content, motivation for engaging, behaviours observed and outcomes reported.

Methods We selected 50 threads across five

\section{Key messages}

- Contraceptive forums do not challenge traditional clinical care or result in decreased use of offline medical advice.

- Contrary to concerns about inaccurate information shared on forums, we found little evidence of this in the forums we investigated.

- Forums continue to provide an essential service beyond clinical consultations; however, significant work is required by the user to access this information.
\end{abstract} English-speaking public forums, which contained more than 1000 contraceptive-specific threads. We generated a stratified sample of these threads $(n=250)$ and then completed a qualitative thematic analysis.

Results Forum users seek urgent help, emotional support and the detailed accounts of others. The work of posting on forums is significant and includes framing the question to generate the desired response type, managing responses and assessing their value. Conversations were consistently framed in relation to healthcare and were important for preparing for, understanding and responding to consultations. Most of the technical information was accurate or corrected within the conversation. For most users this enquiry was part of a broader decision-making process and there was no evidence that users planned to make decisions based on forum discussions alone.

Conclusions Our analysis has implications for healthcare organisations that offer or signpost to online information on contraception. It suggests that improvements in the online 'wrap around' information are needed to help decide when to consult, prepare for the consultation, understand the information given and manage postconsultation questions.

\section{BACKGROUND}

Women in the UK spend up to 30 years avoiding unintended pregnancy. ${ }^{1}$
Difficulty finding acceptable contraception is associated with inconsistent use which increases risk of pregnancy, and half of pregnancies in England and Wales are unintended. ${ }^{2}$ High-quality contraceptive information may support the ability to find an acceptable method of contraception and, therefore, may support effective use. ${ }^{3}$

UK guidance on quality contraceptive services requires a full choice of contraceptive options, comprehensive information and decision-making support. ${ }^{4}$ Guidance specifies the need to discuss the risks, benefits, side effects, medical contraindications, instructions for use, and family and personal views on all methods to be considered. This is an ambitious task in a time-limited consultation, ${ }^{5}$ and users often supplement the information provided in consultations with their own online research. ${ }^{6}$

Fifty-four per cent of adults in the UK search for health information online. ${ }^{6}$ Discussion forums enable people to ask personal contraceptive questions or view or respond to the questions that others have asked in an interactive context that is visible by a large audience who may have relevant knowledge or similar 
experiences to share. The value of forums as a source of health information has been questioned, ${ }^{7}$ particularly their role in promoting misinformation or misconceptions. ${ }^{8}$

Forums are a space where people can search for any information regarding contraception and may therefore be useful to understand gaps in current information provision. An analysis of these conversations may therefore be of interest to anyone providing contraceptive information online. We were particularly interested in the content of forum discussions (What is being talked about?), the reasons for having these conversations on forums (What is the motivation for engaging on forums in particular?), the characteristics of the discussion (What behaviours could be observed within these conversations?) and the reported outcomes of the discussion. To explore these areas, we analysed discussions from five online contraceptive discussion forums to inform our thinking on new options for contraceptive information.

\section{Aim}

The study aim was to explore the content of discussions, motivation for engagement, behaviours observed and reported outcomes within five large online contraceptive forums.

\section{Ethics}

Following the British Sociological Association (BSA) report ${ }^{9}$ we did not seek ethical approval for this study. The BSA guidelines suggest that qualitative research on publicly accessible forum data does not require ethical approval or informed consent if an adequate anonymisation process is undertaken. The ethical approach adopted by this study also adheres to wider established guidance. ${ }^{10-13}$ All data discussed in the study are presented following an anonymisation process, so that the initial source cannot be discovered. This procedure includes not referencing URL links of forum posts, paraphrasing quotations and the removal of identifiable information (eg, usernames and email addresses).

\section{METHODS}

Using two internet search engines (Google and Bing) TC searched the terms "contraceptive discussion forum" and "online contraceptive conversation" and identified seven active forums or subforums in English that were dedicated to contraception. Inclusion criteria were a group of posts set up as a conversation among users (a thread) that was publicly accessible without membership restrictions. All of these forums had over 100 users, and more than 1000 contraceptive-specific threads. We completed a preliminary descriptive analysis of the initial seven forums and selected five

Table 1 Description of the five forums investigated in more detail

\begin{tabular}{|c|c|c|c|c|c|}
\hline Overview & Mumsnet & The Student Room & Woman's Health & SH:24 & Reddit \\
\hline Forum size (posts) & $1000+$ & $1000+$ & $1000+$ & $1000+$ & $1000+$ \\
\hline Methods discussed (n) & $\begin{array}{l}\text { Coil (IUD or IUS)=19 } \\
\text { Pill(S)=17 } \\
\text { Injection=3 } \\
\text { Patch=0 } \\
E C=0 \\
\text { Implant }=3 \\
\text { General }=5 \\
\text { Ring }=0 \\
\text { Condom }=0 \\
\text { Sterilisation=2 } \\
\text { Natural planning=3 } \\
\text { Withdrawal }=0\end{array}$ & $\begin{array}{l}\text { Coil (IUD or IUS) }=0 \\
\text { Pill(s)=32 } \\
\text { Injection }=1 \\
\text { Patch }=0 \\
E C=4 \\
\text { Implant }=5 \\
\text { General }=6 \\
\text { Ring }=0 \\
\text { Condom }=2 \\
\text { Sterilisation }=0 \\
\text { Natural planning }=0 \\
\text { Withdrawal }=0\end{array}$ & $\begin{array}{l}\text { Coil (IUD or IUS) }=8 \\
\text { Pill(s)=22 } \\
\text { Injection }=2 \\
\text { Patch }=0 \\
E C=3 \\
\text { Implant }=2 \\
\text { General }=6 \\
\text { Ring }=3 \\
\text { Condom }=3 \\
\text { Sterilisation }=1 \\
\text { Natural planning }=0 \\
\text { Withdrawal }=0\end{array}$ & $\begin{array}{l}\text { Coil (IUD or IUS)=11 } \\
\text { Pill(s)=13 } \\
\text { Injection=4 } \\
\text { Patch=2 } \\
\mathrm{EC}=4 \\
\text { Implant=4 } \\
\text { General }=2 \\
\text { Ring=1 } \\
\text { Condom }=3 \\
\text { Sterilisation=4 } \\
\text { Natural planning=1 } \\
\text { Withdrawal }=1\end{array}$ & $\begin{array}{l}\text { Coil (IUD or IUS)=22 } \\
\text { Pill(S)=17 } \\
\text { Injection=2 } \\
\text { Patch=1 } \\
\mathrm{EC}=0 \\
\text { Implant=1 } \\
\text { General }=3 \\
\text { Ring }=1 \\
\text { Condom }=2 \\
\text { Sterilisation=0 } \\
\text { Natural planning=0 } \\
\text { Withdrawal }=1\end{array}$ \\
\hline $\begin{array}{l}\text { Average response rate } \\
\text { (responses per question) } \\
\text { (n) }\end{array}$ & 12 & 14 & 8 & 10 & 15 \\
\hline Moderator presence & No & No & Yes & Yes & No \\
\hline $\begin{array}{l}\text { Expertise level of } \\
\text { moderator }\end{array}$ & $\mathrm{N} / \mathrm{A}$ & N/A & Non-expert & Expert & $\mathrm{N} / \mathrm{A}$ \\
\hline $\begin{array}{l}\text { Estimated age group of } \\
\text { users }\end{array}$ & $\begin{array}{l}25+\text { years (mention of } \\
\text { families) }\end{array}$ & $\begin{array}{l}\leq 24 \text { years (users in } \\
\text { education) }\end{array}$ & $\begin{array}{l}\text { Older } 30+\text { years users } \\
\text { frequently referenced } \\
\text { their children, their } \\
\text { long-term relationships }\end{array}$ & Mixture of all ages & Mixture of all ages \\
\hline $\begin{array}{l}\text { Characteristics of the } \\
\text { conversations }\end{array}$ & $\begin{array}{l}\text { Welcoming, friendly, } \\
\text { positive, open, } \\
\text { supportive }\end{array}$ & $\begin{array}{l}\text { Vibrant, youthful, } \\
\text { supportive, open, LGBT+ } \\
\text { friendly }\end{array}$ & $\begin{array}{l}\text { Appears to be a } \\
\text { community in its } \\
\text { own right with well- } \\
\text { established norms and } \\
\text { preferences. }\end{array}$ & $\begin{array}{l}\text { Inclusive, professional, } \\
\text { highly personal }\end{array}$ & $\begin{array}{l}\text { Vibrant, supportive, open, } \\
\text { LGBT+ friendly, inclusive } \\
\text { Evidence of a mix of } \\
\text { religious and cultural } \\
\text { expectations }\end{array}$ \\
\hline
\end{tabular}

EC, emergency contraception; IUD, intrauterine device; IUS, intrauterine system; LGBT+, lesbian, gay, bisexual, trans and plus; N/A, not available. 
forums/subforums to provide a sample with variability in age of user, the presence of a moderator, and level of moderator knowledge (table 1).

We created a manageable dataset for analysis by selecting the 50 most recent threads across each of the five forums $(n=250)$. The selection criteria for these threads was a minimum of six responder replies, and a focus on a contraceptive concern raised by an original poster (OP). We selected a randomised stratified sample by assigning the 250 threads a number and using a random number generator to select 10 threads from each forum providing a total of 50 threads for thematic analysis. We completed a formal qualitative analysis of this dataset supplemented by simple counting to quantify some elements of our findings.

\section{Analysis}

Following the random selection of 50 threads, which included 591 individual posts, both authors followed an established data familiarisation process ${ }^{14}$ through repeated reading of the 50 discussion threads to identify emergent themes. We then completed a full thematic analysis $^{14}$ using Nvivo 12 to explore what was being talked about, what was the motivation for engaging with a forum and what behaviours could be observed from forum conversations. We coded the original posts into these emerging themes and the discussion that responded to them separately. Throughout the analysis process we met frequently to ensure themes accurately represented the data. Our coding strategy is given in online supplemental appendix 1.

Following this thematic analysis, we conducted a simple 'count' analysis ${ }^{15} 16$ to provide an overview of the size of the dataset, and to quantify some aspects of our findings including the quantity of factually inaccurate data presented on the forum, and the contraceptive methods discussed. This enabled us to describe the whole of our dataset in terms of the type of information presented, and the nature of enquiries and responses.

\section{RESULTS}

\section{Description of the forums}

All forums had some similar characteristics, including response rate and contraceptive methods discussed (table 1). Users across all forums showed high levels of trust and openness, evidenced by detailed discussion of highly personal material. We observed differences between forums in user profiles, conversation tone and the moderator role. One forum (SH:24) had an identified medically trained moderator (PB) who provided technical advice, whereas Woman's Health had users who assumed a moderator role because of their apparent knowledge and the frequency of their posts. SH:24 and Woman's Health both had forum users who would refer questions directly to these moderators instead of the whole forum. The approaches within Reddit and The Student Room seemed cautious with a low threshold for offering medical advice, whereas Mumsnet users frequently offered self-management advice based on personal long-term experience.

User age could be estimated from the questions posed and the responses received within each forum. Forums used by an older user group (eg, Mumsnet) included concerns such as post-pregnancy contraception, contraception suitable for women of different ages and age-related fertility concerns. Users of this forum appeared more knowledgeable than other forum users regarding contraceptive use and technical knowledge. Younger users (eg, those using The Student Room) raised concerns about first-time contraceptive use, access to contraception away from home and discussions of first-time sexual encounters.

\section{Content of forum discussions}

Most contraceptive methods were discussed in all of the forums, with the 'coil' (either the intrauterine device/system) and 'pills' being the most popular topics for discussion in all except The Student Room, where the 'coil' was not discussed at all, possibly due to the younger age of the participants.

Why are people using forums for contraceptive advice, do they receive the type of information they request, and do they act upon the information received?

People used forums to meet an urgent need for help when other services were inaccessible, to contextualise their own experience with reference to the experience of others, to help manage a face-to-face consultation, to gain emotional support, and to access nonbiomedical approaches to the management of side effects. The key advantage of a forum in this context is the rapid response from a large audience including detailed personal accounts and overt expressions of support. Users were often clear about their intentions and what type of response they preferred. Both the questions and the responses included detailed, specific and personal descriptions that engaged the reader and conveyed or responded to a particular type of need. Table 2 illustrates the range of reasons for posting and the responses they generated.

Many posts referenced a clinical interaction, for example, asking for information about a planned procedure or for clarification or questioning of the clinical advice obtained, or for the experience of others postprocedure. Forums were also used to obtain advice on how best to use the available face-to-face resource, for example, when to consult, who to consult or how to obtain a particular outcome from a consultation. Some posters used the forum when they were worried about another person and could not seek a consultation on their behalf, or where face-to-face care was difficult to access. We categorised these information needs in relation to face-to-face care as those arising when clinical consultations are inappropriate, inconvenient or insufficient (table 3). 
Table 2 Reasons for posting and responses offered on forums

\begin{tabular}{ll}
\hline Reason for posting & $\begin{array}{l}\text { Example quotes of reasons for } \\
\text { posting }\end{array}$ \\
\hline $\begin{array}{l}\text { Urgently seeking help, } \\
\text { and unsure of what to do }\end{array}$ & $\begin{array}{l}\text { "...So I had a Mirena fitted yesterday... } \\
\text { had awful awful craps... I can't help being } \\
\text { completely paranoid that it's moved... I just } \\
\text { want some reassurance it's normal?..." }\end{array}$ \\
& \\
Seeking to learn from the & \\
experience of others & "...I'm new here but really wanted second \\
opinions on the issue I'm having. Partner \\
and I had a burst condom incident the day \\
after my last period ended. The next day \\
I went and got Levonelle (it was within \\
24hours from the incident)... Has anyone \\
had a Levonelle failure?... Ah, I'm going \\
crazy with worry. Any advice would be \\
much appreciated!..."
\end{tabular}

Seeking nonconventional, technical information
Categories of responses given to OP post and their frequency

Sharing practical advice

threads, with 73 mentions)

Questioning the OPs interpretation of

symptoms (occurred in 10 threads, with 22 mentions)
Example quotes of responses

Sharing practical advice:

"... Had mine in yesterday. 1/2 day of

cramping totally manageable with some

ibuprofen...

Questioning interpretation of symptoms:

"... You're definitely normal OP! It won't have moved, I had the same and once it passed I was so happy I'd had it fitted...

Sharing of similar experience (occurred Sharing of similar experience: in 29 threads, with 98 mentions) Acknowledgement of variation in personal experience (occurred in 12 threads, with 23 mentions) Sharing of negative experiences (occurred in 18 threads, with 28 mentions)

"... Yes, it failed for me and I ended up with an ectopic pregnancy..."

Acknowledgement of variation:

"...I think if you're this late... you're not pregnant. Obviously, some people might experience it differently, but I doubt you are as FRERs are so sensitive...."

Sharing of negative experiences:

"... Levonelle messed with my cycle for a good 6 weeks..."

\section{Reference own consultation:}

Reference own clinical consultation (occurred in 18 threads, with 33 mentions) Demonstrate a high level of knowledge (occurred in 30 threads, with 93 mentions)

Linking to external knowledge sources. (occurred in 2 threads with 6 mentions)

\section{How are users consulting forums for contraceptive advice?}

Users frequently requested a specific type of help, for example, technical information, emotional support or the experience of others. To indicate their need users provided detailed information about their circumstances and the extent of their distress in order to facilitate the type of response they required. Having asked a specific question, or specified a type of response, users then actively managed their thread, posting and engaging with some responses more than others to obtain specific information. Typically, a user would post numerous questions within a thread, asking for more detail and clarification; once a significant number of responses had been received they would then effectively end the thread by expressing their gratitude.
"...Thanks@Gxxxxxl@axxxxxs@oxxxk@dxxxxe. I hated it from day 1 and these are more reasons I'll never have it again... I'll get it taken out now...."

\section{How do responders influence the direction of conversations?}

Just as the OPs worked to manage their threads, the responders were also active in influencing the outcome of a conversation. Responders frequently balanced the information within forum threads, for example, countering a thread that was largely positive by sharing their own negative encounters, or encouraging others to think critically about the advice they received within a thread and the signposting given. Responders were sometimes sympathetic, sometimes didactic and 
Table 3 Forum discussions as an adjunct to clinical consultations

\begin{tabular}{|c|c|c|}
\hline Adjunct themes & Adjunct subthemes & Example quotes of adjunct motives \\
\hline $\begin{array}{l}\text { Clinical consultation } \\
\text { inappropriate }\end{array}$ & Posting on behalf of someone else & $\begin{array}{l}\text { "...My daughter has been put on the pill Rigevidon... Having read about it, it's scaring } \\
\text { me... Will she get blood clots, a stroke or even die... she seems fine... Has anyone been } \\
\text { on this pill or have any advice?..." }\end{array}$ \\
\hline $\begin{array}{l}\text { Clinical consultation } \\
\text { inconvenient }\end{array}$ & $\begin{array}{l}\text { Posting because cannot easily access } \\
\text { clinical services }\end{array}$ & $\begin{array}{l}\text { "...My doctor had told me to get the coil but not recommended which one as they don't } \\
\text { provide the service I will need to go to a clinic. I need some information, I wanted the } \\
\text { copper coil but with the heavy periods I don't want to become anaemic. What about } \\
\text { Mirena? Has anyone any experience of either? Advice would be very much appreciated." }\end{array}$ \\
\hline $\begin{array}{l}\text { Clinical consultation } \\
\text { insufficient }\end{array}$ & $\begin{array}{l}\text { Posting on forums for clarification of } \\
\text { information provided in clinical care } \\
\text { Posting on forums, following a } \\
\text { procedure to determine normality } \\
\text { Posting on forums before a procedure, } \\
\text { seeking insight } \\
\text { Posting on forums to question medical } \\
\text { experience }\end{array}$ & $\begin{array}{l}\text { "...I've just started taking the combined pill... never taken any pills before. The person } \\
\text { at the clinic recommended I take a 5-day break instead of } 7 . \text { What is the reason for this } \\
\text { and should i really take the 5-day break or go for the } 7 ? . . . \\
\text { "... I got my implant } 3 \text { days ago. I was told I "wouldn't feel a thing". The insertion was } \\
\text { agony and bled lots. It continued to bleed, and bruise until my entire arm went numb } \\
\text { and it was a constant source of pain. Three days later and the bleeding has gone. It's still } \\
\text { bandaged. Is this normal? Did anyone else get this or did it go wrong?..." } \\
\text { "... I guess I am frightened. I'm more frightened of the operation [female sterlisation] } \\
\text { than the actual decision, what is the operation like and what follows? Thanks in } \\
\text { advance..." } \\
\text { "... I am desperate, I really wanted the coil to be OK and I don't know if I have an } \\
\text { underlying problem that my doctor hasn't recognised?..." }\end{array}$ \\
\hline
\end{tabular}

sometimes critical, but where this occurred unhelpful posts would often be countered.

"...Don't listen to those people who are complaining about sex before marriage, they're just ignorant and trying to make you feel bad, idiots. Of course you made a mistake, it happens. I hope you had a go at the guy for being a liar... he's definitely in the wrong if he flat out denied any chance of having an STD [sexually transmitted disease]..."

\section{Is the information provided accurate?}

Out of the total number of posts $(n=591), 13 \%(n=80)$ contained clinical, technical information including contraceptive effectiveness, the likelihood of side effects, contraindications to use, and explanations of how contraceptives work. A fact check of these references showed that $76 \%(n=61)$ were consistent with current clinical advice. Most of the posts with inaccurate information $(n=19)$ concerned the effectiveness of individual methods, the likelihood of side effects, or confusion about the active ingredients of hormonal methods. Across all posts $(\mathrm{n}=591)$ we discovered $1 \%$ of posts $(n=6)$ had the potential to harm users; all of these posts recommended inappropriate doses of analgesics or alternative therapies to manage adverse symptoms.

\section{Outcomes of consulting a forum}

Thirty-five of the 50 OPs mentioned their intended actions after receiving advice from the forum. Three of the 35 reported significantly changing their course of action, for example, seeking medical advice or stopping their contraceptive method. Two OPs intended to discuss the new information gained through the forum conversations during their next clinical consultation. In 17 threads no clear advice was offered and in 13 threads forum users expressed that forum advice supported their original intentions.

"...I would like to thank everybody who responded to my query. I have taken on board all of your comments and I guess I'll have to go to the appointment with the gynaecologist... so will decide after that..."

\section{DISCUSSION}

Online forums provide rapid responses to urgent problems, detailed accounts of the experiences of 'others like me', emotional support and advice in response to personal questions. The level of activity on contraceptive forums suggests that these spaces are highly valued. All the forums we studied had thousands of active threads on all methods of contraception, and contrary to recent suggestions that forums are becoming less popular, ${ }^{17}$ we found no evidence that this is an outdated form of communication.

Forum users are looking for emotional support and the experience of others that are often unavailable within clinical consultations and at a scale that is not usually available from friends and family. However, the conversations were consistently framed in relation to healthcare, and seemed important in preparing for and responding to consultations. We found no evidence to support the literature suggesting that forum conversations challenge clinical care, or result in decreased use of offline medical advice. ${ }^{18} 19$ Instead forums were used to understand and interpret the clinical approach, and advice was sought to learn how to use clinical care more effectively. Contrary to concerns about inaccurate information shared on forums ${ }^{20-22}$ we found very little inaccurate information, and where this information did occur it was usually corrected.

Using forums involves significant work. Whether this is framing a question or managing a response, 
both OPs and responders direct threads, engage with specific users, counteract critical or unsupportive messages and sift through responses. Despite this work, there is little evidence that forum users altered their actions in response to the advice they received; rather they sought to contextualise their experience with reference to that of others and obtain support within a broader process of making contraceptive decisions. Definitive solutions to the problems posted were neither offered or expected.

\section{CONCLUSIONS AND IMPLICATIONS FOR FUTURE SERVICES}

Our analysis of forum conversations has implications for healthcare organisations that offer or signpost to online contraceptive information. The process of engaging with forums requires significant work; however, forums are highly valued for the depth of user experience and the emotional support they offer, particularly to prepare for, understand and respond to clinical consultations. We think that improvements in the 'wrap around' information provided online to help decide when to consult, prepare for the consultation, understand the information given, and manage post-consultation questions may need more attention on contraceptive information sites. Users also want increased access to detailed information based on the experience of 'others like me', more emotional support and greater reassurance. These findings are another reminder of the emotional work of contraceptive decision-making and the importance of the context. More thinking is required on whether and how this information could or should be offered within health information websites or whether this remains outside the remit of the support provided by healthcare organisations.

\section{Limitations}

We could only analyse the contributions of those who were actively engaging with the forum, namely posting questions and writing responses. It was not possible to present data from the majority of forum users who only read forum information to inform their decisionmaking process, and do not contribute to online discussion. ${ }^{23}$

Contributors TC and PB contributed equally to this article.

Funding This research was self-funded by $\mathrm{SH}: 24$.

Competing interests $\mathrm{PB}$ is Clinical Director of SH:24 and is the moderator on the $\mathrm{SH}: 24$ contraceptive forum.

Patient and public involvement Patients and/or the public were not involved in the design, or conduct, or reporting, or dissemination plans of this research.

\section{Patient consent for publication Not required.}

Provenance and peer review Not commissioned; externally peer reviewed.

Data availability statement All data relevant to the study are included in the article or uploaded as supplementary information. All applicable data are included in the article.
Open access This is an open access article distributed in accordance with the Creative Commons Attribution Non Commercial (CC BY-NC 4.0) license, which permits others to distribute, remix, adapt, build upon this work noncommercially, and license their derivative works on different terms, provided the original work is properly cited, appropriate credit is given, any changes made indicated, and the use is noncommercial. See: http://creativecommons.org/licenses/by-nc/4. $0 /$.

\section{ORCID iD}

Tom Courtenay http://orcid.org/0000-0003-3899-7937

\section{REFERENCES}

1 Wellings K, Brima N, Sadler K, et al. Stopping and switching contraceptive methods: findings from Contessa, a prospective longitudinal study of women of reproductive age in England. Contraception 2015;91:57-66.

2 Wellings K, Jones KG, Mercer CH, et al. The prevalence of unplanned pregnancy and associated factors in Britain: findings from the Third National Survey of Sexual Attitudes and Lifestyles (Natsal-3). Lancet 2013;382:1807-16.

3 Egarter C, Grimm C, Nouri K, et al. Contraceptive counselling and factors affecting women's reproductive choices: results of the CHOICE study in Austria. Reprod Biomed Online 2012;24:692-7.

4 National Institute of Clinical Excellence. Quality standard QS 129. Quality statement 1: contraceptive information and methods. Available: https://www.nice.org.uk/guidance/qs129/ chapter/Quality-statement-1-Contraceptive-information-andmethods [Accessed 19th May 2020].

5 Littlejohn KE, Kimport K. Contesting and differentially constructing uncertainty: negotiations of contraceptive use in the clinical encounter. J Health Soc Behav 2017;58:442-54.

6 Office for National Statistics. Internet access - households and individuals, Great Britain internet access - households and individuals, Great Britain, 2018. Available: https://www. ons.gov.uk/peoplepopulationandcommunity/householdcharact eristics/homeinternetandsocialmediausage/bulletins/internet accesshouseholdsandindividuals/2018 [Accessed 19th May 2020].

7 Cole J, Watkins C, Kleine D. Health advice from internet discussion forums: how bad is dangerous? J Med Internet Res 2016;18:e4-15.

8 Solberg LB. The benefits of online health communities. Virtual Mentor 2014;16:270-4.

9 British Sociological Association. Researching online forums ethics case study, 2016. Available: https://www.britsoc.co.uk/ media/24834/j000208_researching_online_forums_-cs1__v3. pdf [Accessed Last accessed 19th May 2020].

10 Eysenbach G, Till JE. Ethical issues in qualitative research on internet communities. BMJ 2001;323:1103-5.

11 Bassett EH, O’Riordan K. Ethics of internet research: contesting the human subjects research model. Ethics Inf Technol 2001;2:233-47.

12 Kaiser K. Protecting respondent confidentiality in qualitative research. Qual Health Res 2009;19:1632-41.

13 van den Hoonaard WC. Is anonymity an artifact in ethnographic research? J Acad Ethics 2003;1:141-51.

14 Ritchie J. Qualitative research practice: a guide for social science students and researchers. Thousand Oaks: CA Sage Publications, 2003.

15 Corley KG, Gioia DA. Identity ambiguity and change in the wake of a corporate spin-off. Adm Sci Q 2004;49:173-208. 
16 Hannah DR, Lautsch BA. Counting in qualitative research: why to conduct it, when to avoid it, and when to closet it. $J$ Manag Inq 2011;20:14-22.

17 Pendry LF, Salvatore J. Individual and social benefits of online discussion forums. Comput Human Behav 2015;50:211-20.

18 Mesch GS. Social relationships and Internet use among adolescents in Israel. Soc Sci Q 2001;82:329-39.

19 Nie N, Hillygus DS, Erbring L. Internet use, interpersonal relations, and sociability. The Internet in Everyday Life $2002 ; 1: 215-43$.
20 Bellander T, Landqvist M. Becoming the expert constructing health knowledge in epistemic communities online. Inf Commun Soc 2020;23:507-22.

21 Schmidt K, Ernst E. Assessing websites on complementary and alternative medicine for cancer. Ann Oncol 2004;15:733-42.

22 Air M, Roman SA, Yeo H, et al. Outdated and incomplete: a review of thyroid cancer on the World Wide Web. Thyroid 2007;17:259-65.

23 van Mierlo T. The 1\% rule in four digital health social networks: an observational study. J Med Internet Res 2014;16:e33-9. 